\title{
TNFRSF9 Suppressed the Progression of Breast Cancer via the p38MAPK/PAX6 Signaling Pathway
}

\section{Xun Zhu ( $\square$ zhuxun202102@sina.com )}

Department of General Surgery, The Second Affiliated Hospital of Soochow University

Xiaorong Liu

Department of General Surgery, The Second Affiliated Hospital of Soochow University

\section{Yehui Zhou}

Department of General Surgery, The Second Affiliated Hospital of Soochow University Chenglin Qin

Department of General Surgery, The First People's Hospital of Yancheng

\section{Research Article}

Keywords: breast cancer, TNFRSF9, p38, MAPK, PAX6

Posted Date: January 12th, 2022

DOI: https://doi.org/10.21203/rs.3.rs-1232265/v1

License: (9) This work is licensed under a Creative Commons Attribution 4.0 International License. Read Full License 


\section{Abstract}

Background Worldwide, Breast cancer is the most common cancer in females. Endocrine therapy can effectively treat $85 \%$ of breast cancer patients, but $15 \%$ of patients could only be treated with chemotherapy and surgery, and the prognosis is much worse. Immunotherapy is the novel treatment for breast cancer that PD-1 and CTLA-4 antibodies have shown evidence of immune modulation in breast cancer drug trials.

Methods and Result In this study, we report that TNFRSF9 regulates the cell proliferation, invasion, and apoptosis of breast cancer cells through regulating the phosphorylation of $\mathrm{p} 38$, thus further regulate the expression of PAX6. In both breast cancer tissues and cell lines, the levels of TNFRSF9 are significantly decreased, and breast cancer cell development will be promoted with knockdown of TNFRSF9. Moreover, we identify that downregulation of TNFRSF9 can upregulate the phosphorylated p38 (p-p38) and PAX6. We further elucidate that p-p38 is essential for PAX6 expression that p38 phosphorylation inhibitor can reverse the upregulation of PAX6 and suppress cell proliferation, invasion, and promote apoptosis in breast cancer cells.

Conclusions In summary, this study proposed a novel TNFRSF9/p38/PAX6 axis that contributes to tumor suppression, which suggests a potential immunotherapy target for breast cancer.

\section{Introduction}

Breast cancer was one of the most common malignant tumors in female. According to the American Cancer Society, in 2017, 255180 new breast cancer cases and 41070 breast cancer deaths are projected to occur in the United States. ${ }^{1}$ In China, the incidence and mortality of breast cancer are increasing that there are 272400 new breast cancer cases and 70700 breast cancer deaths are projected to occur in $2015 .^{2}$ Due to highly heterogeneous, potentially aggressive, and complex biological features of breast cancer, more detailed molecular understanding of breast cancer is essential to help develop early diagnosis methods and novel therapies for breast cancer patients.

When the system fails to remove transformed cells, the host develops cancer. Therefore, cancer immunotherapy is to restore or induce immune cells, such as cytotoxic T cells, to identify, target, and destroy cancer cells. ${ }^{3}$ The programmed cell death protein 1 (PD-1) mediates the immune checkpoint pathway, and it is normally expressed by activated T cells, B cells, dendritic cells, and natural killer cells. While PD-1 interacts with its ligands, programmed death ligand 1 (PD-L1) and PD-L2, the T-cell activation and proliferation are inhibited, preventing autoimmunity in normal tissues. ${ }^{4}$ However, several types of tumor cells, including gastrointestinal cancer, ovarian cancer, and breast cancer, are also found to highly express PD-L1, helping the tumor cells escape the immune system. ${ }^{5-7}$ It seems that disrupt the interaction between PD-1 and PD-L1 may promote tumor cells to be attacked by cytotoxic T cells, and after many pieces of research, several PD-1/PD-L1 inhibitors have been developed and showed excellent results in treatment. ${ }^{8,9}$ 
The tumor necrosis factor receptor (TNFR) superfamily member TNFRSF9 (also known as 4-1BB or CD137) is a T cell costimulatory receptor first found to express on activated antigen-presenting cells. Later research also found it on regulatory T cells, activated natural killer T cells, and activated NK cells. ${ }^{10}$ The complete roles of TNFRSF9 are not fully Activated TNFRSF9 will induce survival signaling in T cells, but TNFRSF9 deficient T cells are hyperproliferative. ${ }^{11}$ Despite the uncertainty, TNFRSF9 has been found to affect tumor cells. Expression of TNFRSF9 on Hodgkin and Reed-Sternberg cells mediates immune escape. ${ }^{12}$ TNFRSF9 also acts as a tumor suppresser that overexpression of TNFRSF9 can inhibit tumor proliferation and invasion and induce apoptosis. ${ }^{13,14}$ Many research show that anti-TNFRSF9 antibodies can boost cancer immunotherapies. For example, the agonistic antibody potentiated the antitumor activity of the anti-HER2 antibody in the mouse models of breast cancer. ${ }^{15}$ However, the underlying mechanism is unknown and waiting for exploration.

p38 mitogen-activated protein kinase (p38 MAPK) is an important family member of the MAPK family, and it involves many signal pathways that can affect cell differentiation, apoptosis, and autophagy. ${ }^{16}$ Cannons et al. ${ }^{17}$ reported that aggregation of TNFRSF9 could induce p38 activation. The transcription factor Paired box 6 (PAX6) is the downstream target of p38 that the transactivation domain of PAX6 will be phosphorylated by $338 .{ }^{18}$ In human cancer, PAX6 is proposed to promote cell proliferation and invasion in colon cancer. ${ }^{19}$ The inhibition of PAX6 in lung cancer cell lines also inhibits cell proliferation. ${ }^{20}$ Moreover, the overexpression of PAX6 is found in retinoblastoma. ${ }^{21}$ In the lymph node metastasis status of breast cancer, PAX6 is switched from methylated to methylation status in the progression of metastasis, which suggests novel biomarkers for breast cancer metastasis. ${ }^{22}$

In this study, we reveal that through upregulating TNFRSF9 in breast cancer, the PAX6 expression can be downregulated through inhibiting p38 phosphorylation and preventing tumor growth. As a result, the agonistic TNFRSF9 antibody may be a novel molecule for breast cancer therapies.

\section{Methods}

\subsection{Patient samples}

A total of 30 pairs of breast cancer tissues and paracancerous tissues were collected from breast cancer patients from the Second Affiliated Hospital of Jiaxing University. All the patients were female and aged between 30 to 60 years. They were pathologically diagnosed as nonspecific invasive breast cancer for the first time and had not received chemotherapy before the study. Clinicopathological features of patients were collected for further data analysis. This study was approved by the Ethics Committee of the Second Affiliated Hospital of Jiaxing University (JXEY-ZFYJ041) and the Laboratary Animal Ethics Committee of JXMC (JUMC2020-131). All related patients were informed about the research and have signed the informed consent letters. After extraction, the tissues were quickly frozen and stored at $-80^{\circ} \mathrm{C}$ for RNA and protein extraction. 


\subsection{Cell lines and cell culture}

The breast cancer cell lines, including MCF-7, MDA-MB-453, MDA-MB-231, ZR-75-30, BT474, and human non-tumorigenic breast epithelial cell line MCF-10A were cultured in 10\% FBS DMEM medium under an environment of $5 \% \mathrm{CO}_{2}$ and $37^{\circ} \mathrm{C}$.

\subsection{Cell transfection}

Small interfering RNA against TNFRSF9 (si-TNFRSF9) and small interfering RNA negative control (si-NC) were used to knockdown the expression of TNFRSF9 in the MCF-7 and ZR-75-30 cell lines. pcDNA 3.1 plasmids with the full length of TNFRSF9 (pcDNA3.1-TNFRSF9) and related negative control (NC) were used to upregulate TNFRSF9 in the MCF-7 and ZR-75-30 cell lines. All mentioned factors were then transfected into cells through Lipofectamine ${ }^{T M} 2000$, adhered to the provided protocol.

\subsection{Quantitative real-time PCR (qRT-PCR)}

Total RNA in breast cancer tissues, paracancerous tissues, and cells was extracted by TRIzol reagent. qRT-PCR was performed by using the ABI 7900HT RealTime PCR System based on SYBR Green assay. The $2^{-\Delta \Delta C t}$ method was used to evaluate the RNA expression level.

\subsection{Western Blot}

The whole-cell lysate was prepared in RIPA protein solubilization buffer. Proteins were quantified using BCA kits and blocked with $5 \%$ skim milk at room temperature for one hour. After washing with PBS three times, proteins were incubated with primary antibodies (TNFRSF9, p-p38 MAPK, p38 MAPK, PAX6, and GAPDH) overnight at $4^{\circ} \mathrm{C}$. The membrane was then washed with PBS 3 times, 5 minutes each, followed with incubation with secondary antibody $(1: 2000)$ and incubation at $25^{\circ} \mathrm{C}$ for 2 hours. The band was visualized using ECL luminescence solution in a dark room. The images were developed and analyzed with the ChemiDocXRS+ system.

\subsection{Cell proliferation detection}

Cell Counting Kit-8 (CCK-8) was used to detect cell proliferation. Cells of each group ( $5 * 105 \mathrm{cells} / \mathrm{ml}$ ) were incubated in a 96-well plate $(100 \mu \mathrm{l} /$ well) for 72 hours in an incubator. After removing the medium, $10 \mu \mathrm{l}$ CCK-8 solution was added to each well of the plate. The plate was incubated in the dark for 3 hours. The results were determined by measuring the light absorbance at $450 \mathrm{~nm}$ on a microplate reader.

5'-bromo-2'-deoxyuridine (BrdU) assay was also performed to examine the cell proliferation ability of the

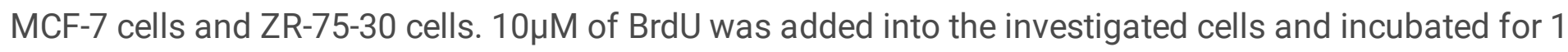


hour. After that, the cells were resuspended at $4^{\circ} \mathrm{C}$ and frozen in $70 \% \mathrm{~V} / \mathrm{V}$ ethanol. The cells were collected and washed with PBS by centrifuge. Then the cells were cultured with $\mathrm{HCl}(2 \mathrm{M})$ at room temperature for a half-hour. After washing twice with PBS, the anti-BrdU antibody was applied to the cells and cultured in the dark for 20 minutes. Finally, images were developed with fluorescent microscopy.

\subsection{Cell invasion}

Transwell assay was used to assess the cell invasion ability of MCF-7 cells and ZR-75-30 cells. The top chamber of Transwell were pretreated with $300 \mu \mathrm{l}$ serum-free media and incubated for 2 hours at room temperature. Each group of cells were suspended in serum-free media and diluted to $5^{\star} 10^{5} \mathrm{cell} / \mathrm{ml} .300$ $\mu \mathrm{l}$ cell suspension was added into the top chamber of Transwell, and the lower chamber was filled with $500 \mu \mathrm{l}$ medium containing FBS. After 24 hours of incubation at $37^{\circ} \mathrm{C}$, the inserts were stained with $0.1 \%$ crystal violet for another 20 minutes. After washing, five views (200x) of the upper chamber's lower layer were chosen randomly to observe and count the invaded cells under the microscope.

\subsection{Cell apoptosis evaluation}

Cell apoptosis was detected through Annexin V-FITC/PI double staining and was analyzed by flow cytometry. Cells were harvested and washed with PBS, and then resuspended in $500 \mu$ l binding buffer, which contained $5 \mu \mathrm{L}$ Annexin V-FITC and $5 \mu \mathrm{L}$ propidium iodide. After 10 minutes of incubation in the dark at room temperature, the samples were applied for flow cytometry (FCM) analysis.

\subsection{Xenograft subcutaneous tumor formation assay}

Five to six weeks old female BALB/C mice were anesthetized and were given a dorsal subcutaneous injection of MCF-7 cells, suspended in $100 \mu$ of Matrigel $(n=10)$. Five mice's tumors were injected with the pLV-TNFRSF9 plasmid, and five tumors were injected with the negative control plasmid (NC). The volume of the tumor was measured every three days after the therapy. The mice were euthanized after 18 days, and the areas containing transplanted cells were measured, sliced, and stained with H\&E, bcl-2 antibodies, or TNFRSF9 antibodies. Animal studies were approved by the ethics committee of the Second Affiliated Hospital of Jiaxing University and followed the guidelines of Care and Use of Laboratory Animals of China.

\subsection{Statistical analysis}

Statistical analysis was performed using SPSS software (Version 22.0). Data were presented as mean \pm standard deviation $(x \pm s)$ of at least three biological repeats. $t$-test was used for the intergroup comparison, and two-sided chi-squared test was used to compare groups. Values of $p<0.05$ indicate statistical significance. 


\section{Result}

\subsection{The expression of TNFRSF9 in breast cancer is significantly decreased, and related to metastasis and malignant}

We conducted qRT-PCR assays to detect the mRNA expression of TNFRSF9 in breast cancer tissues and paracancerous normal tissues collected from 30 patients. As shown in Fig. 1A, the expression of TNFRSF9 in breast cancer tissues was remarkably lower than their nearby non-tumor tissues $\left({ }^{\star \star *} \mathrm{p}<0.001\right)$. The western blot assay result (Fig. 1B) indicates the TNFRSF9 protein expression's downregulation in eight matched breast cancer tissues and normal tissues. Low expression of TNFRSF9 mRNA and TNFRSF9 protein was observed in five breast cancer cell lines (Fig. 1C-D, ${ }^{\star \star \star} p<0.001$ ). We also compared the clinicopathological features between low TNFRSF9 expression patients and high TNFRSF9 expression patients (Table 1). Patients with high TNFRSF9 were less likely to have lymphoid metastasis $(p=0.0007)$ and lower Malignant Tumors (TNM) stage $(p=0.0016)$. The above results indicate that dysregulation of TNFRSF9 may have an essential role in breast cancer progression.

\section{Table 1}

Association analysis of TNFRSF9 expression and the clinicopathological features in 30 breast cancer patients 
Characteristics

Low High

$(n=20) \quad(n=10)$

Number

30

20

10

Ages (years)

$0.5921^{\mathrm{a}}$

$\leq 55$

19

12

7

$>55$

11

8

3

Tumor size

$0.5839^{a}$

$\leq 2 \mathrm{~cm}$
$>2 \mathrm{~cm}$
$H R$ (estrogen receptor) status

10

6

4

20

14

6

Negative

14

10

$0.6048^{a}$

Negative
Positive

HER2 status

16

10

4

Negative

17

13

11

$0.7945^{a}$

Positive

3

9

4

Lymph node metastasis

$0.0007^{\mathrm{a}}$

No
Yes

TNM stage

21

92

7

I - II

12

18

2

18

3

III

a Two-sided chi-squared test.

\subsection{Regulating TNFRSF9 expression can mediate p38 phosphorylation and further affect the expression of PAX6}


To further investigate the role of TNFRSF9 in breast cancer, we knockdowned TNFRSF9 through transfecting MCF-7 cells and ZR-75-30 with si-TNFRSF9, as these two cell lines have the lowest TNFRSF9 expression in all the breast cancer cell lines. We also overexpressed TNFRSF9 by transfecting MCF-7 cells and ZR-75-30 with pcDNA3.1-TNFRSF9. qRT-PCR assays were used to determine expression regulation efficiency (Fig. 2A left panel \& Fig. 2C left panel, ${ }^{\star *} p<0.01, * \star \star p<0.001$ ).

We first confirmed the relationship between TNFRSF9, p38, and PAX6. The mRNA expression of PAX6 was detected using qRT-PCR assays. In both the MCF-7 cell line (Fig. 2A right panel) and ZR-75-30 cell line (Fig. $2 \mathrm{C}$ right panel), the mRNA expression of PAX6 was increased with TNFRSF9 downregulation $\left({ }^{* \star} p<0.01,{ }^{* \star *} p<0.001\right)$ and decreased with TNFRSF9 upregulation $(* \star p<0.01)$. As the phosphorylation status of p38 cannot be determined by mRNA, western blot assays were used to assess p-p38 protein expression. In both the MCF-7 cell line (Fig. 2B) and ZR-75-30 cell line (Fig. 2D), with TNFRSF9 knockdown, TNFRSR9 protein expression decreased, p-p38 protein expression increased, PAX6 protein expression increased. In contrast, p38 protein expression remained not significantly changed compared with the knockdown negative controls $\left({ }^{\star} p<0.05,{ }^{* \star} p<0.01\right)$. In contrast, with TNFRSF9 overexpression, TNFRSR9 protein expression increased, p-P38 protein expression decreased remarkably, PAX6 protein expression decreased while $\mathrm{p} 38$ protein expression remained not significantly changed when compared with the overexpression negative controls $\left({ }^{\star} p<0.05,{ }^{* \star} p<0.01,{ }^{* \star}{ }^{*} p<0.001\right)$. The above results indicate that TNFRSR9 mediates $\mathrm{p} 38$ phosphorylation and PAX6 protein expression.

\subsection{Dysregulated TNFRSF9 expression affected cell proliferation, invasion, and apoptosis}

Next, we investigated the dysregulation effect of TNFRSF9 in tumor development. The CCK-8 assays were performed to exam the cell proliferation. In both the MCF-7 cell line (Fig. 3A) and ZR-75-30 cell line (Fig. 3C), when compared with the negative controls, cell proliferation increased with TNFRSF9 knockdown and decreased with TNFRSF9 overexpression. BrdU assays were also performed to exam the cell proliferation. Similarly, comparing with the negative controls, in both MCF-7 cell line (Fig. 3B) and ZR-7530 cell line (Fig. 3D), cell proliferation increased with TNFRSF9 knockdown $\left({ }^{*} p<0.05\right)$ and decreased with TNFRSF9 overexpression ( $\left.{ }^{\star} p<0.05,{ }^{*} p<0.01\right)$. Transwell assays were performed to investigate the cell invasion ability (Fig. 4A \& Fig. 4B). Comparing with the negative control, in both cell lines, knockdown TNFRSF9 enhanced cell invasion ability $(* \star * p<0.001)$ and overexpress TNFRSF9 impaired cell invasion ability ( $* \star p<0.01)$. ). The cell apoptosis was examed through flow cytometry in both cell lines (Fig. 4C \& Fig. 4D). The apoptotic rate decreased when knockdowned TNFRSF9 $\left({ }^{*} \mathrm{p}<0.05\right)$ and increased when overexpressed TNFRSF9 ( $\left.{ }^{\star \star *} p<0.001\right)$. These results suggest that TNFRSF9 is a suppresser of breast cancer malignancy, and activate TNFRSF9 could suppress breast cancer progression.

\subsection{TNFRSF9 mediated PAX6 through p-p38 that inhibiting p38 phosphorylation could restore PAX6 expression from}




\section{TNFRSF9 knockdown}

We found that TNFRSF9 dysregulation affects p38 phosphorylation but not p38 expression previously, so we inhibited p38 phosphorylation to determine the regulation axis. qRT-PCR assays and western blot assays were used to determine the efficiency of the p38 phosphorylation inhibitor (p38 MAPK-IN-1). In both the MCF-7 cell line (Fig. 5A) and ZR-75-30 cell line (Fig. 5C), when knockdowned TNFRSF9 with p38 phosphorylation inhibitor, the downregulated TNFRSF9 mRNA expression was not affected, and the mRNA expression of PAX6 was decreased compared to the negative control level $\left(* \star p<0.01,{ }^{\star \star \star} p<\right.$ 0.001). The western blot assays (Fig. 5B \& fig. 5D) confirmed that the p38 phosphorylation inhibitor inhibited the protein expression of p-p38 without affecting TNFRSF9 protein expression and restored the PAX6 protein expression to low level as the negative control $\left({ }^{\star} p<0.05,{ }^{\star \star} p<0.01\right.$, $\left.{ }^{\star \star \star} p<0.001\right)$.

We further investigated the restoration effect of p38 in tumor development. The CCK-8 assays were performed to exam the cell proliferation. In both the MCF-7 cell line (Fig. 6A) and ZR-75-30 cell line (Fig. $6 \mathrm{C})$, comparing with the TNFRSF9 knockdown group, cell proliferation decreased with p38 phosphorylation inhibitor. BrdU assays were also performed to exam the cell proliferation. Similarly, comparing with the TNFRSF9 knockdown group, in both MCF-7 cell line (Fig. 6B) and ZR-75-30 cell line (Fig. 6D) cell proliferation decreased significantly with p38 phosphorylation inhibitor ( ${ }^{\star \star} p<0.01$, $* \star \star p<<$ 0.001). Transwell assays were performed to investigate the cell invasion ability (Fig. 7A \& Fig. 7B). Comparing with the TNFRSF9 knockdown group, in both MCF-7 and ZR-75-30 cell lines, inhibiting p38 phosphorylation impaired cell invasion ability compared to the negative control level $(* \star p<0.01)$. The cell apoptosis was examed through flow cytometry in both cell lines (Fig. 7C \& Fig. 7D). The apoptotic rate decreased when knockdowned TNFRSF9 $\left({ }^{\star} \mathrm{p}<0.05\right)$ and increased when p38 MAPK-IN-1 was given to siTNFRSF9 transfected cells ( $\left.{ }^{\star \star *} p<0.001\right)$. All these findings suggest that TNFRSF9 suppresses breast cell carcinogenesis through inhibiting p38 phosphorylation and inhibit PAX6 protein expression as a result.

\subsection{Overexpression of TNFRSF9 can reduce malignancy in breast cancer cell-induced tumor formation}

We further gave a subcutaneous injection of MCF-7 cells transfected with or without pLV-TNFRSF9 to mice to induce tumor formation. Tumors induced by pLV-TNFRSF9 injected MCF-7 cells were significantly smaller in size compared to tumors induced by NC injected MCF-7 cells (Fig. 8A and 8B). Furthermore, the tumors' pathological slides were stained with H\&E (Fig. 8C), Bcel-2 antibody, or TNFRSF9 antibody (Fig. 8D). The H\&E image indicated that the pLV-TNFRSF9 injected tumor was less malignant. The immunohistochemical image showed less Bcl-2 expression and more TNFRSF9 expression in the pLVTNFRSF9 injected tumor. qRT-PCR assays were performed to evaluate the mRNA expression of TNFRSF9 and PAX6 in the tumor tissues (Fig. 8E). In all five pLV-TNFRSF9 injected tumors, the mRNA expression of TNFRSF9 was significantly upregulated (upper panel) and the mRNA expression of PAX6 was significantly downregulated (lower panel) $\left({ }^{\star} p<0.05,{ }^{\star \star} p<0.01\right.$, $\left.{ }^{\star \star *} p<0.001\right)$. The western blot assay result (Fig. 8F) indicates that in eight matched tumor tissues, the protein expression of TNFRSF9 was 
significantly promoted with pLV-TNFRSF9 injection. In contrast, the protein expression of p-p38 and PAX6 were significantly suppressed, and the protein expression of p38 remains unchanged. Therefore, agonistic TNFRSF9 antibody may be a novel therapy for breast cancer patients.

\section{Discussion}

Breast cancer is the most common cancer in women all around the world. Although the endocrine therapy is potent that the five-year breast cancer-specific survival could be over $99 \%$, only $70 \%$ of breast cancer patients whose tumor cells overexpressed estrogen receptor or progesterone receptor proteins are fit this therapy. For the $15 \%$ triple-negative breast cancer (TNBC) patients whose tumor does not overexpress estrogen receptor, progesterone receptor, or HER2, they can only be treated with chemotherapy and surgery, and have a worse prognosis, and more likely to relapse. ${ }^{23}$

Immunotherapy is a revolutionized cancer therapy that activates the tumor-specific immune response to eradicate the tumor. Several immune biomarkers have been identified in breast cancer, which can be used for prognosis and prediction. For example, HER-2 ${ }^{+}$breast cancers and TNBCs are more likely to express the PD-L1 in the tumor microenvironment than luminal breast cancers. ${ }^{24,}{ }^{25}$ Therefore, breast cancer is very suitable for immunotherapy, and several drugs have been tested in breast cancer trials with evidence of immune modulation. CTLA-4 expresses T-cell and binding CD80/CD86 to limiting T-cell activation during the immune response's priming phase. Two anti-CTLA-4 agents, tremelimumab and ipilimumab, have been developed and used in many tumor types. In a breast cancer drug test, tremelimumab significantly increased the ratio of $\mathrm{ICOS}^{+} / \mathrm{FoxP}^{+} \mathrm{CD}^{+} \mathrm{T}$ cells in most patients and stable the disease for more than 12 weeks in $42 \%$ of patients. ${ }^{26}$ Several agonistic antibodies targeting other inhibitory immune checkpoint molecules, such as lymphocyte-activation gene 3 (LAG3) and T cell immunoglobulin and mucin domain-containing molecule 3 (TIM3) are also in development. ${ }^{27}$ In our study, we reveal a possible inhibitory immune checkpoint molecule TNFRSF9 for breast cancer treatment that the agonistic antibody of TNFRSF9 may be effective for breast cancer immunotherapy.

We show that TNFRSF9 inhibits tumor progression by suppressing p38 phosphorylation and the protein expression of the downstream target of p-p38, PAX6. PAX genes are essential for cancer cell survival. ${ }^{28}$ According to Zong et al. ${ }^{29}$, downregulation of PAX6 in vitro can suppress cell viability, DNA synthesis, and colony formation. The tumorigenesis in xenograft nude mice was also significantly inhibited. In this study, we confirmed that downregulation of PAX6 expression could suppress breast cancer development in vivo and inhibit tumorigenesis in xenograft nude mice. We also revealed that TNFRSF9 and p-p38 were the upstream regulators of PAX6. However, we did not confirm that p38 is the direct downstream target of TNFRSF9 or PAX6 is the direct target of p-p38. Jie et al. have reported that $\beta$-catenin binds to the proximal region of PAX6 promoter during osteoclast differentiation to induce PAX6 expression, and p38 could cause $\beta$-catenin degradation. Thus there is a p38/ $\beta$-catenin/PAX6 axis in the negative regulation of osteoclastogenesis. ${ }^{30}$ It is highly likely to exist a similar axis in breast cancer cells between TNFRSF9 and p38 or p38 and PAX6, which could be further investigated in the future. 


\section{Conclusion}

In conclusion, we disclosed for the first time that PAX6 is regulated by a novel TNFRSF9/p38 pathway. PAX6 can further promote breast cancer development. Our study indicates that this novel TNFRSF9/p38/PAX6 axis contributes to suppressing tumorigenesis. We also propose an agonistic TNFRSF9 antibody as a potential antibody for breast cancer immunotherapy.

\section{Declarations}

\section{Acknowledgments}

The authors are grateful to all the participators and patients who offered help and support. The authors would like to acknowledge Jiaxing Science and Technology Plan Project (No. 2020AD30101).

\section{Funding}

This study was supported by Jiaxing Science and Technology Plan Project (No. 2020AD30101).

\section{Availability of data and materials}

The datasets analyzed for the present study are available from the corresponding author upon reasonable request.

\section{Authors' contributions}

$X Z$ conceived and designed the study. XL And YZ searched and selected publications. XL and YZ wrote and revised the paper. $C Q$ and $X L$ analyzed the data. All authors critically reviewed the manuscript and approved the final draft.

\section{Ethics approval and consent to participate}

This study was approved by the Ethics Committee of the Second Affiliated Hospital of Jiaxing University (JXEY-ZFYJ041) and the Laboratary Animal Ethics Committee of JXMC (JUMC2020-131)

\section{Patient consent for publication}

Informed consent of each research participant was obtained. 


\section{Competing interest}

The authors have declared that no competing interest exists.

\section{References}

1. Siegel, R. L.; Miller, K. D.; Jemal, A., Cancer statistics, 2017. CA: A Cancer Journal for Clinicians2017, $67(1), 7-30$.

2. Chen, W.; Zheng, R.; Baade, P. D.; Zhang, S.; Zeng, H.; Bray, F.; Jemal, A.; Yu, X. Q.; He, J., Cancer statistics in China, 2015. CA: A Cancer Journal for Clinicians2016, 66 (2), 115-132.

3. Chen, D. S.; Irving, B. A.; Hodi, F. S., Molecular Pathways: Next-Generation Immunotherapy-Inhibiting Programmed Death-Ligand 1 and Programmed Death-1. Clinical Cancer Research2012, 18 (24), 6580-6587.

4. Taube, J. M.; Anders, R. A.; Young, G. D.; Xu, H.; Sharma, R.; McMiller, T. L.; Chen, S.; Klein, A. P.; Pardoll, D. M.; Topalian, S. L.; Chen, L., Colocalization of inflammatory response with B7-h1 expression in human melanocytic lesions supports an adaptive resistance mechanism of immune escape. Sci Transl Med2012, 4 (127), 127ra37.

5. Ghebeh, H.; Mohammed, S.; Al-Omair, A.; Qattan, A.; Lehe, C.; Al-Qudaihi, G.; Elkum, N.; Alshabanah, M.; Bin Amer, S.; Tulbah, A.; Ajarim, D.; Al-Tweigeri, T.; Dermime, S., The B7-H1 (PD-L1) T lymphocyteinhibitory molecule is expressed in breast cancer patients with infiltrating ductal carcinoma: correlation with important high-risk prognostic factors. Neoplasia2006, 8 (3), 190-8.

6. Wu, C.; Zhu, Y.; Jiang, J.; Zhao, J.; Zhang, X.-G.; Xu, N., Immunohistochemical localization of programmed death-1 ligand-1 (PD-L1) in gastric carcinoma and its clinical significance. Acta histochemica2006, 108 (1), 19-24.

7. Hamanishi, J.; Mandai, M.; Iwasaki, M.; Okazaki, T.; Tanaka, Y.; Yamaguchi, K.; Higuchi, T.; Yagi, H.; Takakura, K.; Minato, N., Programmed cell death 1 ligand 1 and tumor-infiltrating CD8+ T lymphocytes are prognostic factors of human ovarian cancer. Proceedings of the National Academy of Sciences2007, 104 (9), 3360-3365.

8. Rugo, H. S.; Delord, J. P.; Im, S. A.; Ott, P. A.; Piha-Paul, S. A.; Bedard, P. L.; Sachdev, J.; Le Tourneau, C.; van Brummelen, E. M. J.; Varga, A.; Salgado, R.; Loi, S.; Saraf, S.; Pietrangelo, D.; Karantza, V.; Tan, A. R., Safety and Antitumor Activity of Pembrolizumab in Patients with Estrogen ReceptorPositive/Human Epidermal Growth Factor Receptor 2-Negative Advanced Breast Cancer. Clin Cancer Res2018, 24 (12), 2804-2811.

9. Topalian, S. L.; Sznol, M.; McDermott, D. F.; Kluger, H. M.; Carvajal, R. D.; Sharfman, W. H.; Brahmer, J. R.; Lawrence, D. P.; Atkins, M. B.; Powderly, J. D., Survival, durable tumor remission, and long-term safety in patients with advanced melanoma receiving nivolumab. Journal of clinical oncology2014, $32(10), 1020$.

10. Wang, C.; Lin, G. H. Y.; McPherson, A. J.; Watts, T. H., Immune regulation by 4-1BB and 4-1BBL: complexities and challenges. Immunological Reviews2009, 229 (1), 192-215. 
11. Lee, S. W.; Vella, A. T.; Kwon, B. S.; Croft, M., Enhanced CD4 T cell responsiveness in the absence of 41BB. J Immuno/2005, 174 (11), 6803-8.

12. Ho, W. T.; Pang, W. L.; Chong, S. M.; Castella, A.; Al-Salam, S.; Tan, T. E.; Moh, M. C.; Koh, L. K.; Gan, S. U.; Cheng, C. K.; Schwarz, H., Expression of CD137 on Hodgkin and Reed-Sternberg cells inhibits T-cell activation by eliminating CD137 ligand expression. Cancer Res2013, 73 (2), 652-61.

13. Qian, Y.; Pei, D.; Cheng, T.; Wu, C.; Pu, X.; Chen, X.; Liu, Y.; Shen, H.; Zhang, W.; Shu, Y., CD137 ligandmediated reverse signaling inhibits proliferation and induces apoptosis in non-small cell lung cancer. Med Onco/2015, 32 (3), 44.

14. Zhao, S.; Xing, Y.; Natkunam, Y., Use of CD137 ligand expression in the detection of small B-cell lymphomas involving the bone marrow. Hum Patho/2014, 45 (5), 1024-30.

15. Yonezawa, A.; Dutt, S.; Chester, C.; Kim, J.; Kohrt, H. E., Boosting Cancer Immunotherapy with AntiCD137 Antibody Therapy. Clin Cancer Res2015, 21 (14), 3113-20.

16. Zarubin, T.; Han, J., Activation and signaling of the p38 MAP kinase pathway. Cell Research2005, 15 (1), 11-18.

17. Cannons, J. L.; Choi, Y.; Watts, T. H., Role of TNF receptor-associated factor 2 and p38 mitogenactivated protein kinase activation during 4-1BB-dependent immune response. The Journal of Immunology2000, $165(11), 6193-6204$.

18. Mikkola, I.; Bruun, J. A.; Bjorkoy, G.; Holm, T.; Johansen, T., Phosphorylation of the transactivation domain of Pax 6 by extracellular signal-regulated kinase and p38 mitogen-activated protein kinase. $J$ Biol Chem1999, 274 (21), 15115-26.

19. Li, Y.; Li, Y.; Liu, Y.; Xie, P.; Li, F.; Li, G., PAX6, a novel target of microRNA-7, promotes cellular proliferation and invasion in human colorectal cancer cells. Digestive diseases and sciences2014, 59 (3), 598-606.

20. Zhao, X.; Yue, W.; Zhang, L.; Ma, L.; Jia, W.; Qian, Z.; Zhang, C.; Wang, Y., Downregulation of PAX6 by shRNA inhibits proliferation and cell cycle progression of human non-small cell lung cancer cell lines. PloS one2014, 9 (1), e85738.

21. Wang, J.; Wang, X.; Wu, G.; Hou, D.; Hu, Q., MiR-365b-3p, down-regulated in retinoblastoma, regulates cell cycle progression and apoptosis of human retinoblastoma cells by targeting PAX6. FEBS letters2013, 587 (12), 1779-1786.

22. Urrutia, G.; Laurito, S.; Marzese, D. M.; Gago, F.; Orozco, J.; Tello, O.; Branham, T.; Campoy, E. M.; Roqué, M., Epigenetic variations in breast cancer progression to lymph node metastasis. Clinical \& Experimental Metastasis2015, 32 (2), 99-110.

23. Waks, A. G.; Winer, E. P., Breast Cancer Treatment: A Review. JAMA2019, 321 (3), 288-300.

24. Cimino-Mathews, A.; Thompson, E.; Taube, J. M.; Ye, X.; Lu, Y.; Meeker, A.; Xu, H.; Sharma, R.; Lecksell, K.; Cornish, T. C.; Cuka, N.; Argani, P.; Emens, L. A., PD-L1 (B7-H1) expression and the immune tumor microenvironment in primary and metastatic breast carcinomas. Human Pathology2016, 47 (1), $52-$ 63. 
25. Li, X.; Li, M.; Lian, Z.; Zhu, H.; Kong, L.; Wang, P.; Yu, J., Prognostic role of programmed death ligand-1 expression in breast cancer: a systematic review and meta-analysis. Targeted oncology2016, 11 (6), 753-761.

26. Vonderheide, R. H.; LoRusso, P. M.; Khalil, M.; Gartner, E. M.; Khaira, D.; Soulieres, D.; Dorazio, P.; Trosko, J. A.; Rüter, J.; Mariani, G. L.; Usari, T.; Domchek, S. M., Tremelimumab in Combination with Exemestane in Patients with Advanced Breast Cancer and Treatment-Associated Modulation of Inducible Costimulator Expression on Patient T Cells. Clinical Cancer Research2010, 16 (13), 34853494.

27. Solinas, C.; Gombos, A.; Latifyan, S.; Piccart-Gebhart, M.; Kok, M.; Buisseret, L., Targeting immune checkpoints in breast cancer: an update of early results. ESMO Open2017, 2 (5), e000255-e000255.

28. Muratovska, A.; Zhou, C.; He, S.; Goodyer, P.; Eccles, M. R., Paired-Box genes are frequently expressed in cancer and often required for cancer cell survival. Oncogene2003, 22 (39), 7989-97.

29. Zong, X.; Yang, H.; Yu, Y.; Zou, D.; Ling, Z.; He, X.; Meng, X., Possible role of Pax-6 in promoting breast cancer cell proliferation and tumorigenesis. BMB Rep2011, 44 (9), 595-600.

30. Jie, Z.; Shen, S.; Zhao, X.; Xu, W.; Zhang, X.; Huang, B.; Tang, P.; Qin, A.; Fan, S.; Xie, Z., Activating $\beta-$ catenin/Pax6 axis negatively regulates osteoclastogenesis by selectively inhibiting phosphorylation of p38/MAPK. Faseb j2019, 33 (3), 4236-4247.

\section{Figures}

\section{Figure 1}

The expression of TNFRSF9 in breast cancer decreased. (A) qRT-PCR assay for TNFRSF9 mRNA expression in breast cancer tissues $(n=10)$ and paracancerous tissues. (B) Western blot assays for TNFRSF9 protein expression in breast cancer tissues $(n=8)$ and paracancerous tissues. (C) qRT-PCR assay for TNFRSF9 mRNA expression in breast cancer cell lines. (D) Western blot assays for TNFRSF9 protein expression in breast cancer cell lines. ${ }^{\star \star \star} p<0.001$

\section{Figure 2}

TNFRSR9 mediated p38 phosphorylation and PAX6 expression. (A, C) qRT-PCR assays for TNFRSF9 mRNA expression (left panel) and PAX6 mRNA expression (right panel) in MGF-7 cells (A) or ZR-75-30 cells (C) transfected with si-TNFRSF9 or pcDNA3.1-TNFRSF9. (B, D) Western blot assays for TNFRSF9, pP38, P38 and PAX6 protein expression (left panel), and quantification of protein expression (right panel) in MGF-7 cells (B) or ZR-75-30 cells (D) transfected with si-TNFRSF9 or pcDNA3.1-TNFRSF9. 
A
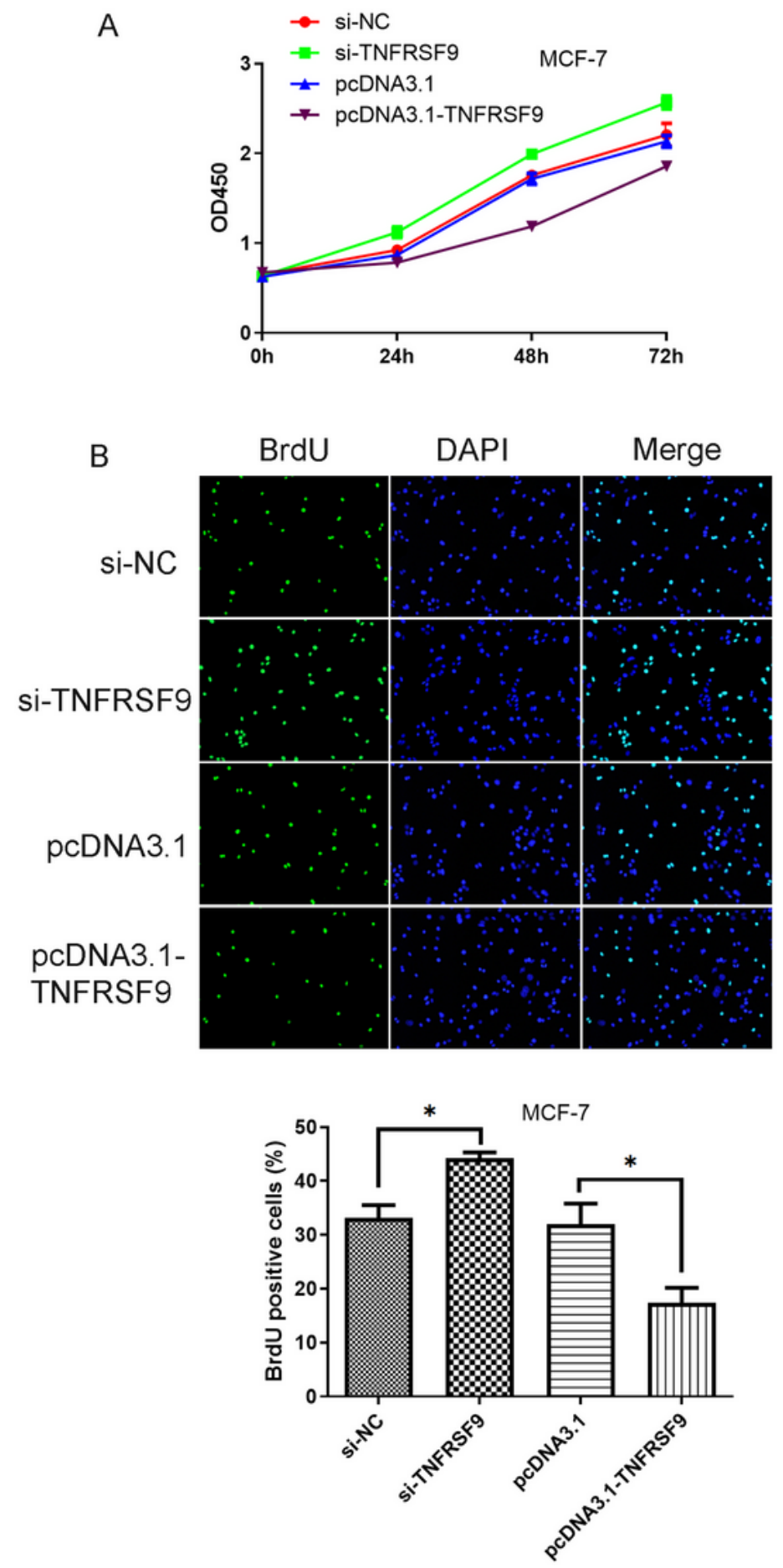

C

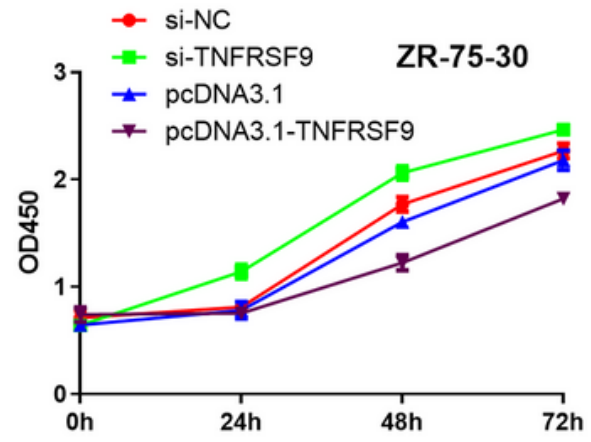

D

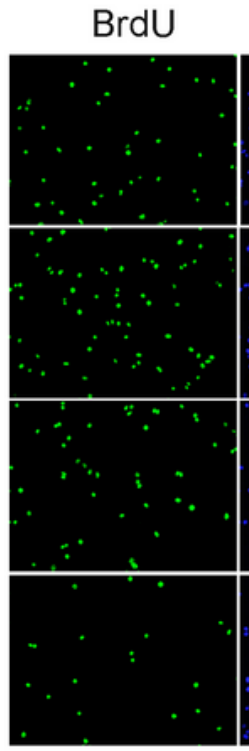

DAPI

Merge
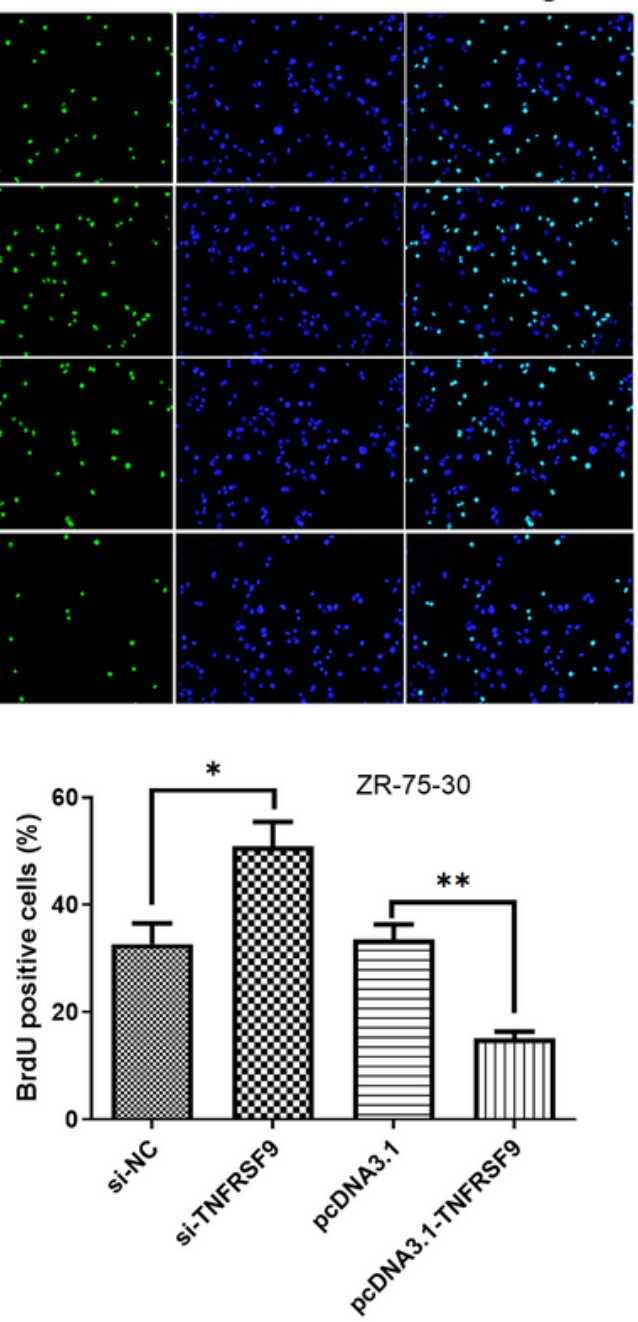

\section{Figure 3}

TNFRSF9 expression affected cell proliferation. (A-B) Cell proliferation assay performed in MGF-7 cells transfected with si-TNFRSF9 or pcDNA3.1-TNFRSF9, including CCK-8 assay (A) and BrdU assay (B). (C-D) Cell proliferation assay performed in ZR-75-30 cells transfected with si-TNFRSF9 or pcDNA3.1-TNFRSF9, including CCK-8 assay (C) and BrdU assay (D). *p $<0.05,{ }^{* *} p<0.01$ 


\section{Figure 4}

TNFRSF9 expression affected cell invasion ability and apoptosis. (A-B) The invasion ability of MGF-7 cells (A) or ZR-75-30 cells (B) transfected with si-TNFRSF9 or pcDNA3.1-TNFRSF9 was determined using transwell invasion assay. Quantitative analysis of the invasive cells in transwell assays was also performed (lower panel). (C-D) Apoptosis assays of MGF-7 cells (C) or ZR-75-30 cells (D) transfected with si-TNFRSF9 or pcDNA3.1-TNFRSF9, and the quantitative analysis of the apoptosis cells (lower panel). *p $<0.05, * \star p<0.01, * \star * p<0.001$ 
A
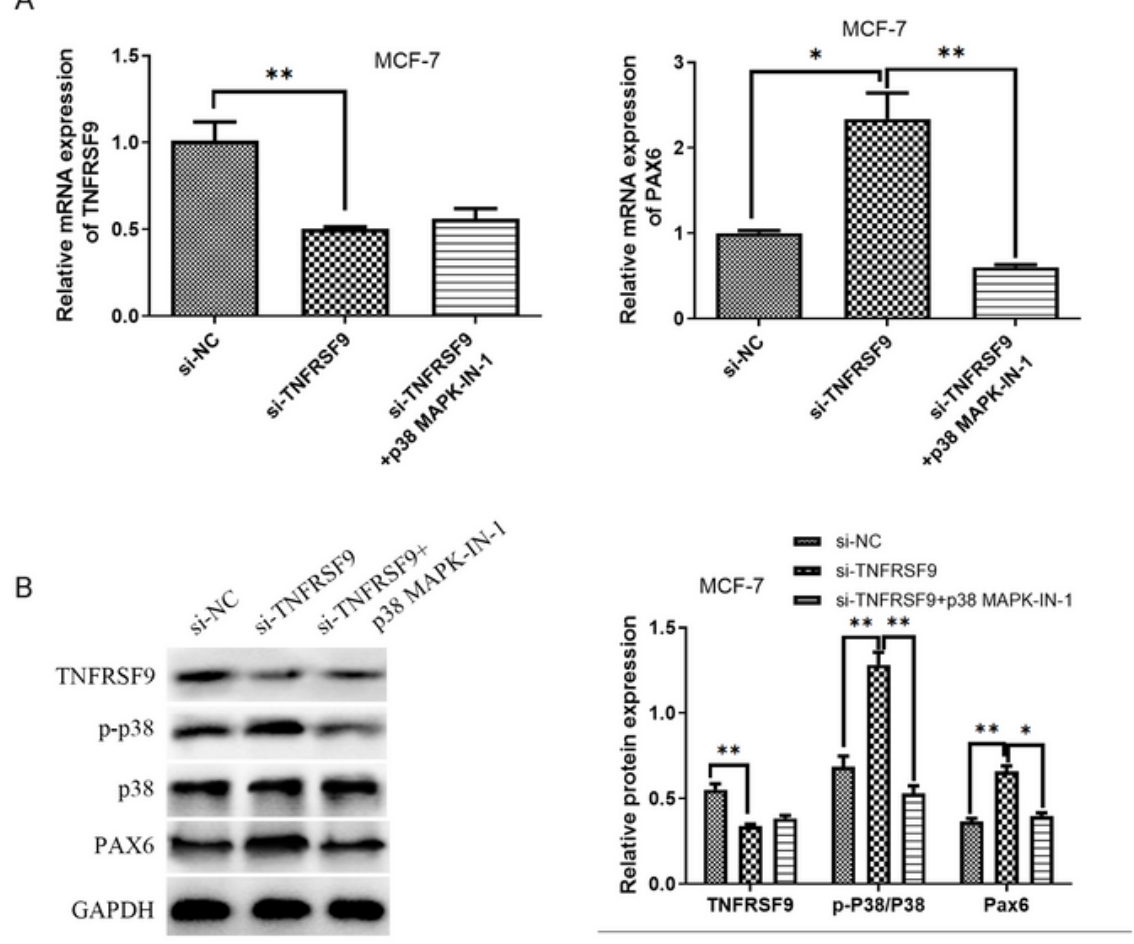

C
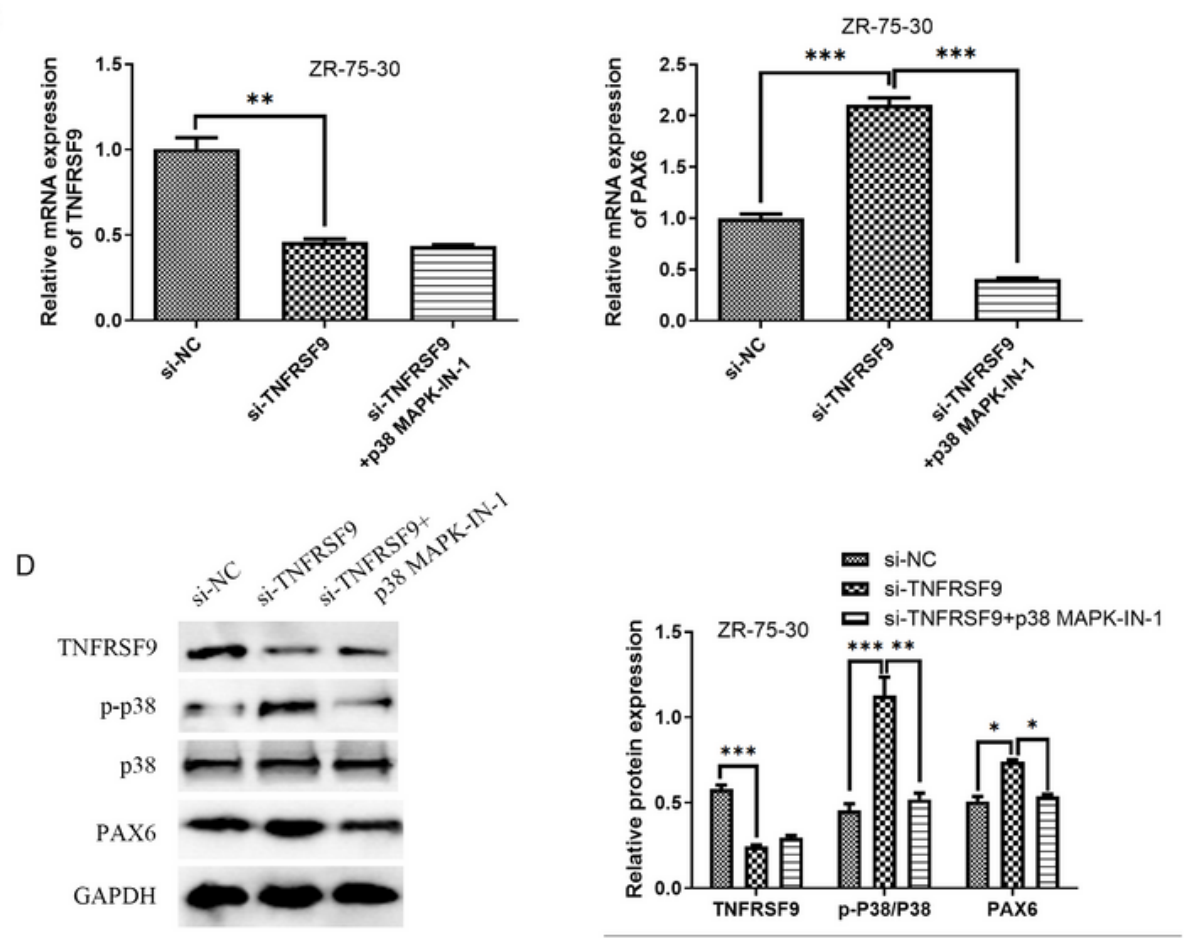

\section{Figure 5}

Inhibition of p38 phosphorylation reversed PAX6 upregulation caused by TNFRSF9 knockdown. (A, C) qRT-PCR assays for TNFRSF9 mRNA expression (left panel) and PAX6 mRNA expression (right panel) in MGF-7 cells (A) or ZR-75-30 cells (C) transfected with si-TNFRSF9 and with or without p38 MAPK-IN-1. $(B, D)$ Western blot assays for TNFRSF9, p-P38, P38 and PAX6 protein expression (left panel), and 
quantification of protein expression(right panel) in MGF-7 cells (B) or ZR-75-30 cells (D) transfected with si-TNFRSF9 and with or without p38 MAPK-IN-1. ${ }^{*} p<0.05,{ }^{*} p<0.01, * \star * p<0.001$

A

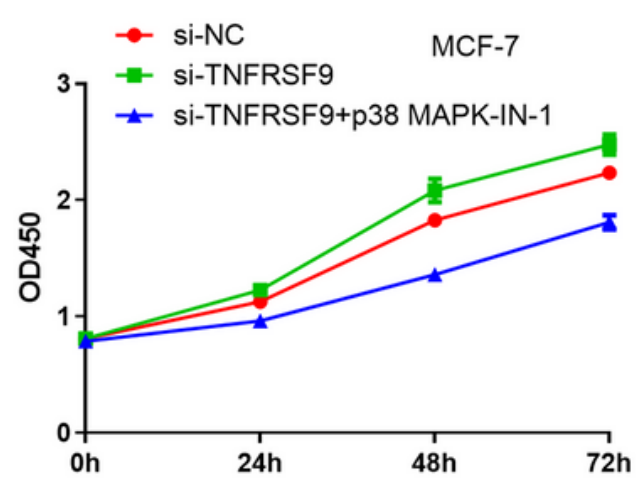

B

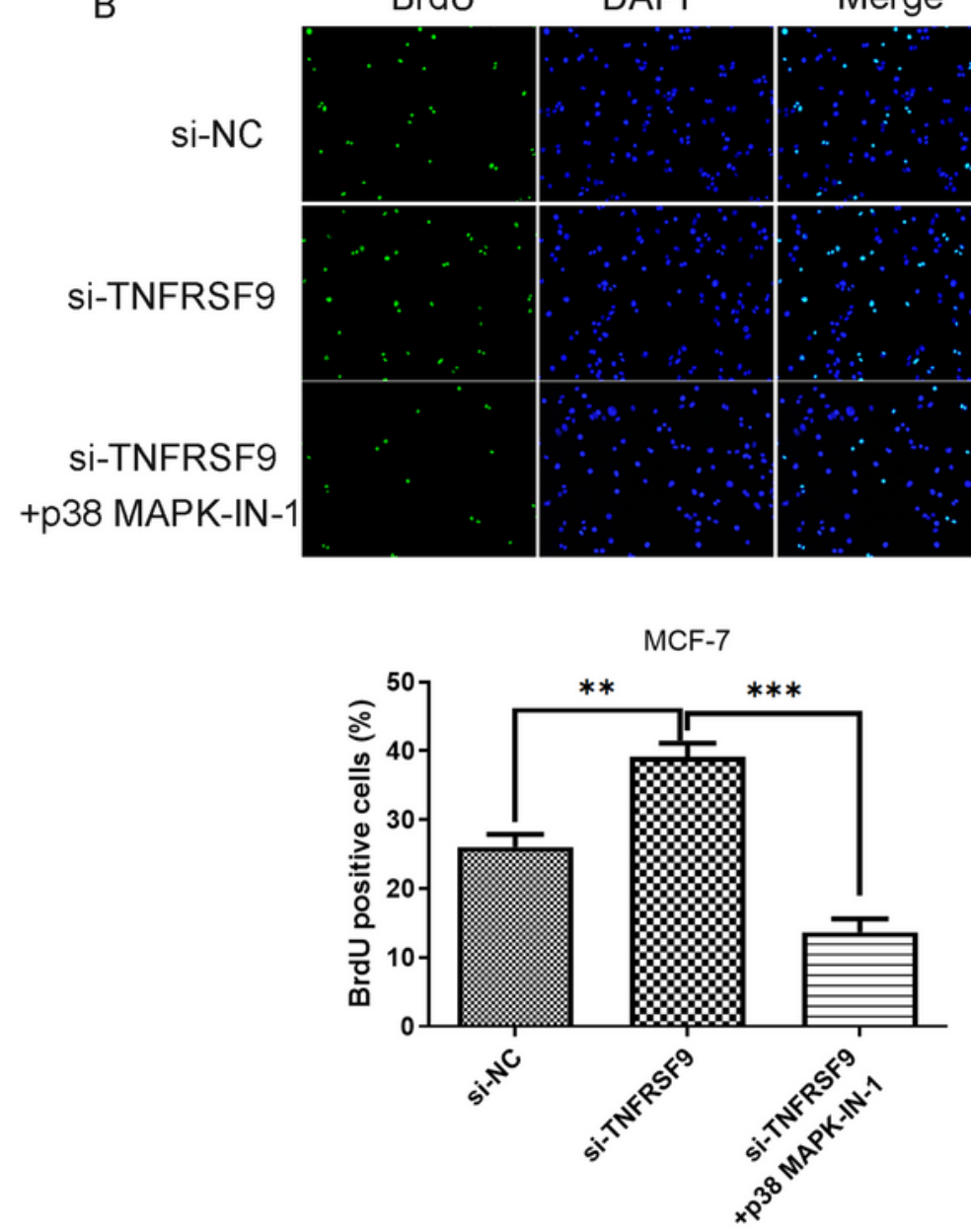

C
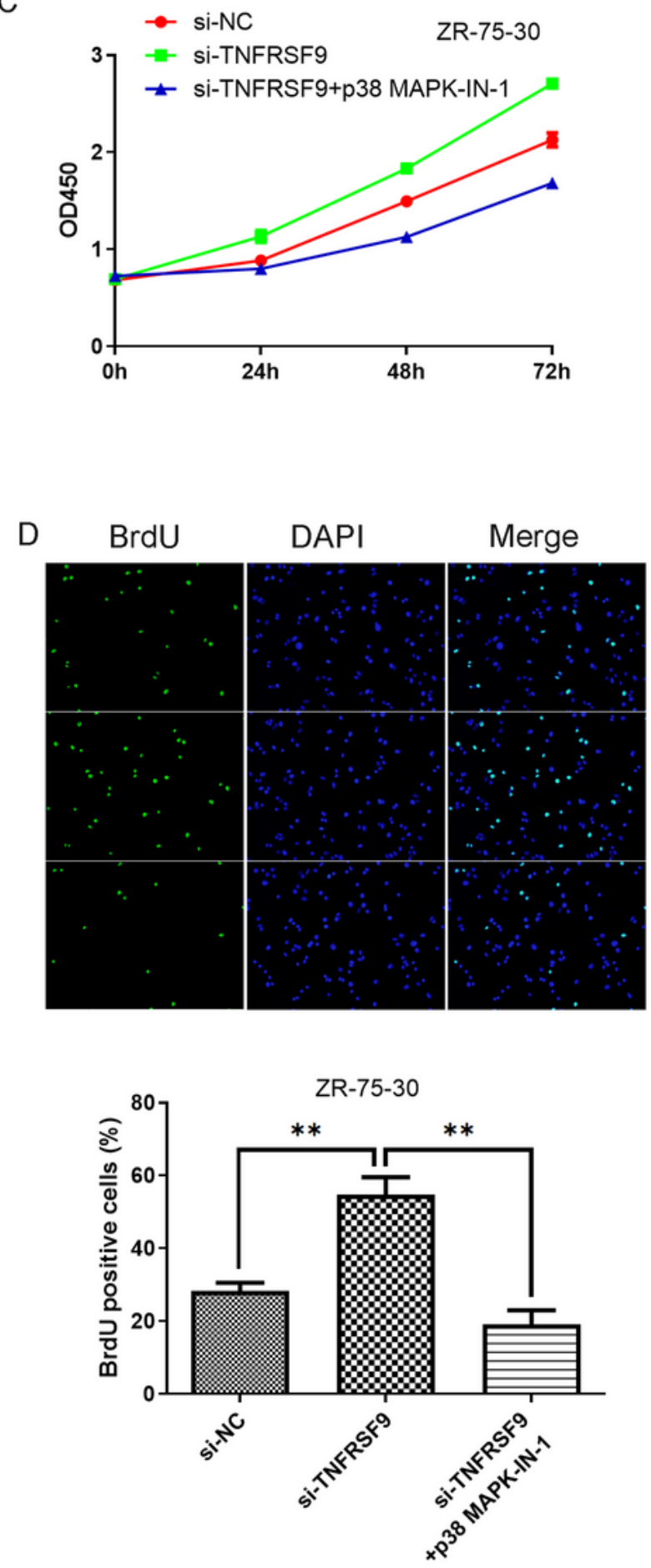

Figure 6

Inhibition of p38 phosphorylation reversed the changes in cell proliferation caused by TNFRSF9 knockdown. (A-B) Cell proliferation assay performed in MGF-7 cells transfected with si-TNFRSF9 and with 
or without p38 MAPK-IN-1, including CCK-8 assay (A) and BrdU assay (B). (C-D) Cell proliferation assay performed in ZR-75-30 cells transfected with si-TNFRSF9 and with or without P38 MAPK-IN-1, including CCK-8 assay (C) and BrdU assay (D). **p $<0.01, * \star * p<0.001$

A

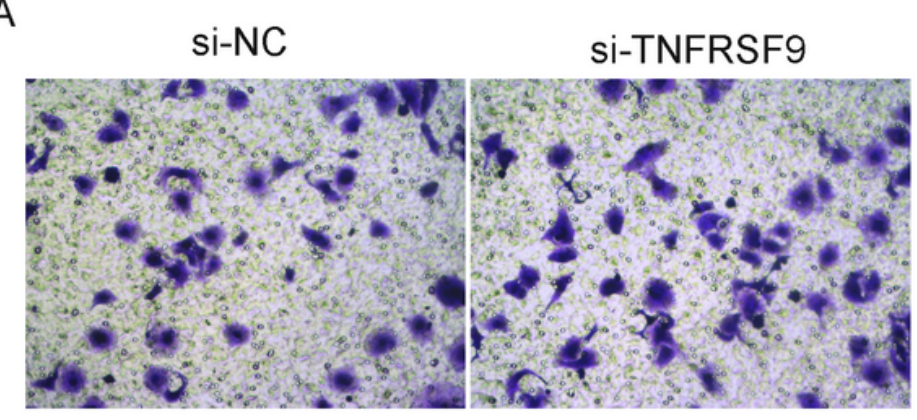

Si-TNFRSF9 $+p 38$ MAPK-IN-1
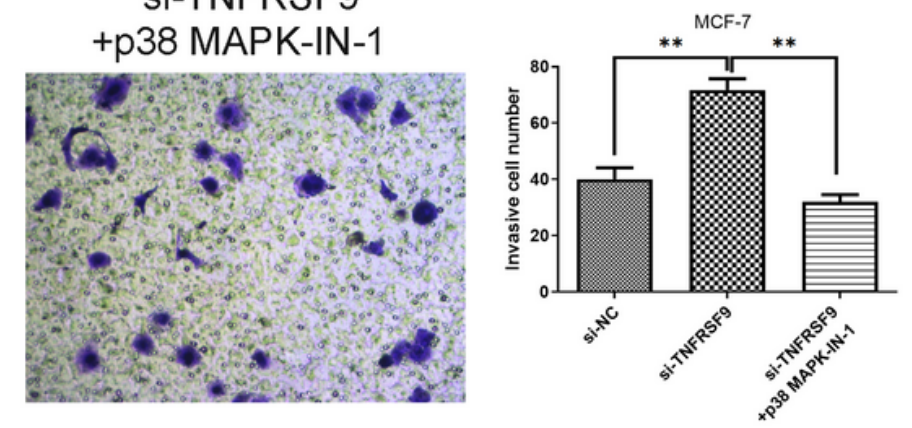

C

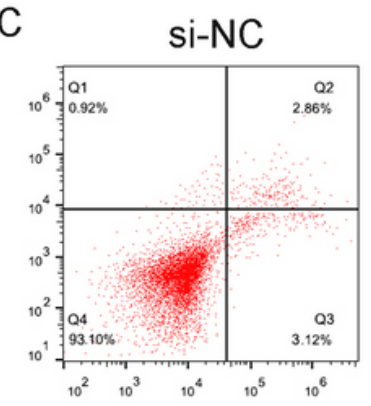

si-TNFRSF9 +p38 MAPK-IN-1
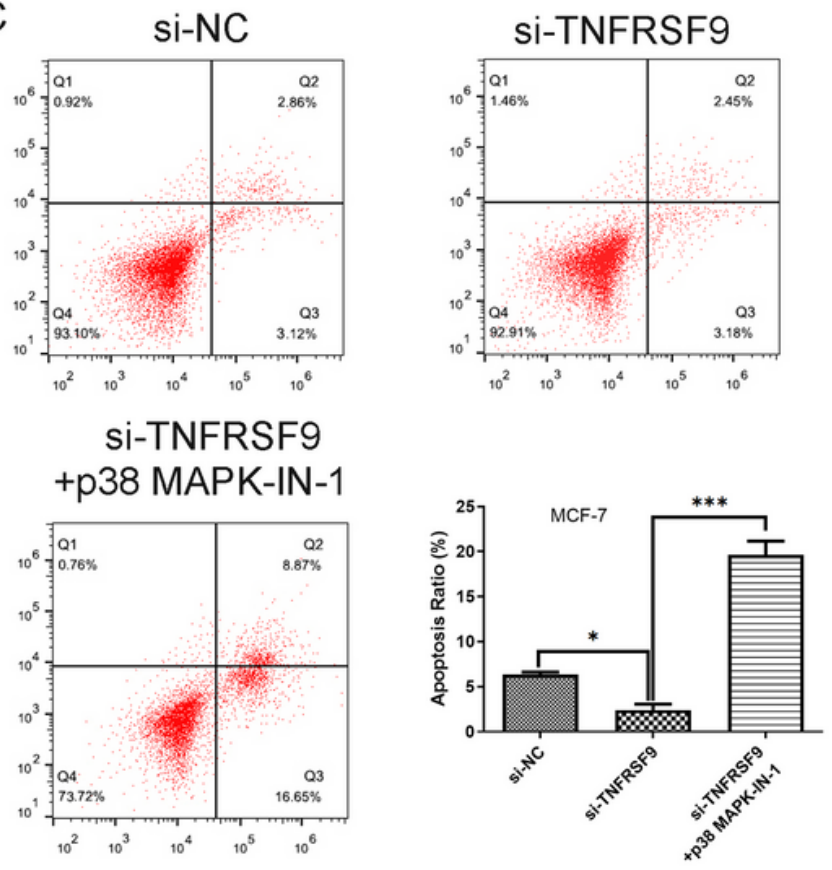

B
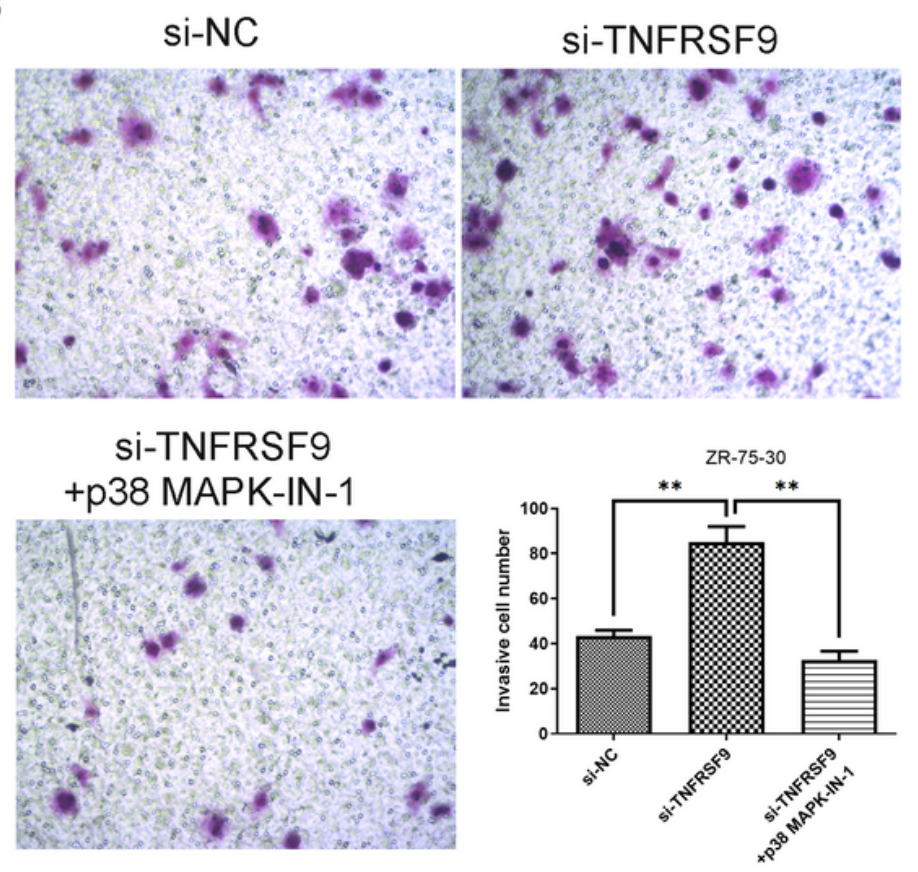

D
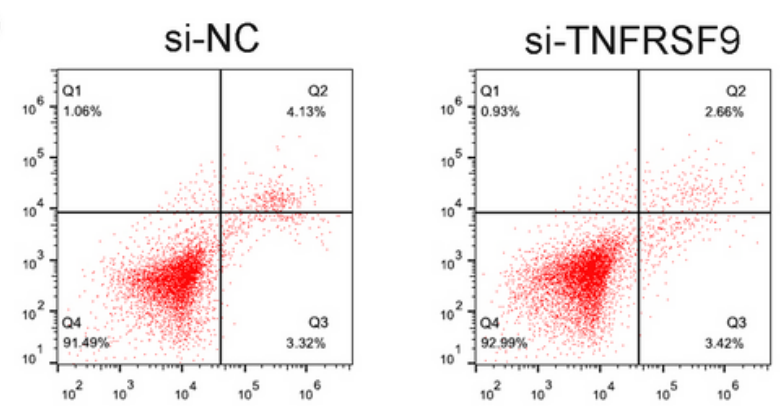

Si-TNFRSF9 + p38 MAPK-IN-1

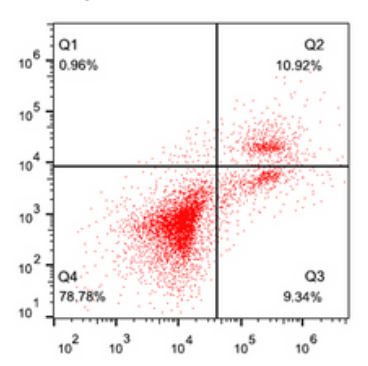

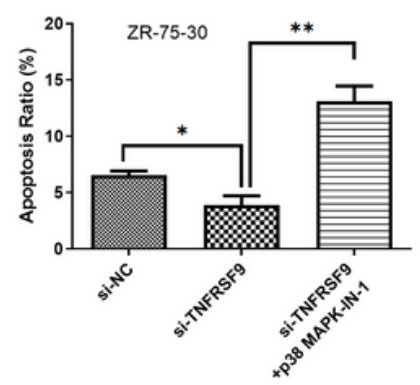

Figure 7

Inhibition of p38 phosphorylation reversed the changes in cell invasion ability and apoptosis caused by TNFRSF9 knockdown. (A-B) The invasion ability of MGF-7 cells (A) or ZR-75-30 cells (B) transfected with 
si-TNFRSF9 and with or without p38 MAPK-IN-1 were determined using transwell invasion assay. Quantitative analysis of the invasive cells in transwell assays was also performed (lower right panel). (CD) Apoptosis assays of MGF-7 cells (C) or ZR-75-30 cells (D) transfected with si-TNFRSF9 and with or without p38 MAPK-IN-1, and the quantitative analysis of the apoptosis cells (lower right panel). ${ }^{\star} \mathrm{p}<0.05$, $\star * p<0.01, * * * p<0.001$
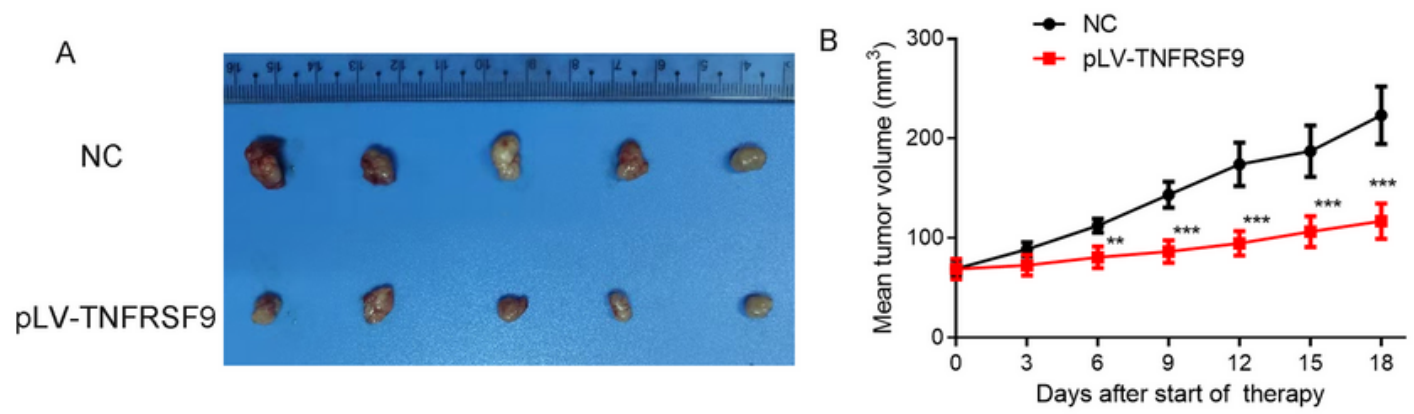

C

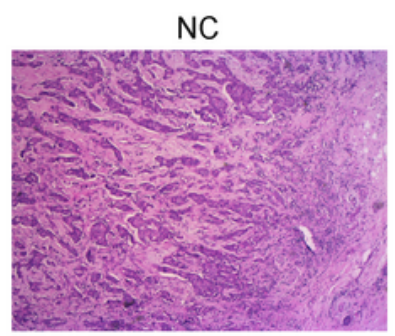

pLV-TNFRSF9

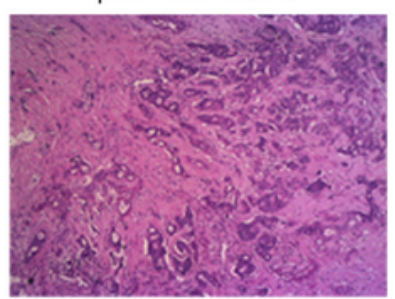

E
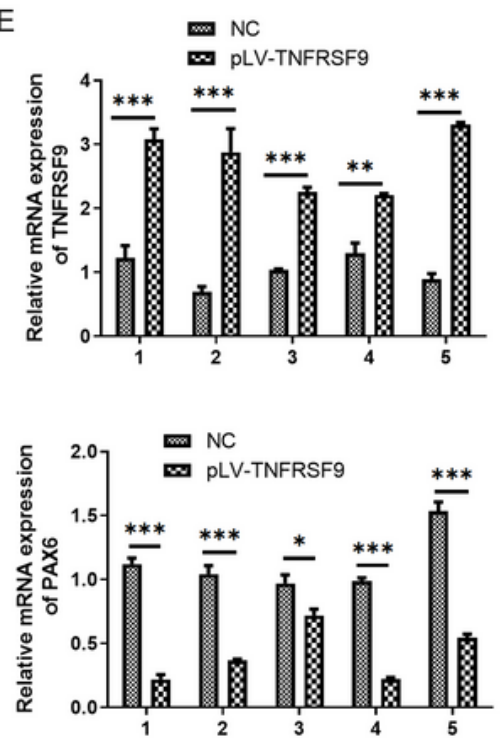

D

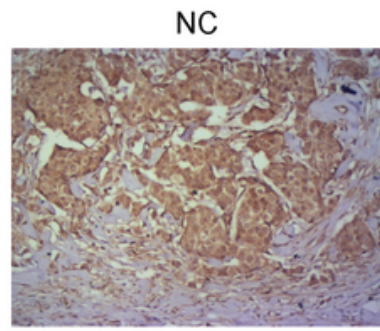

Bcl-2
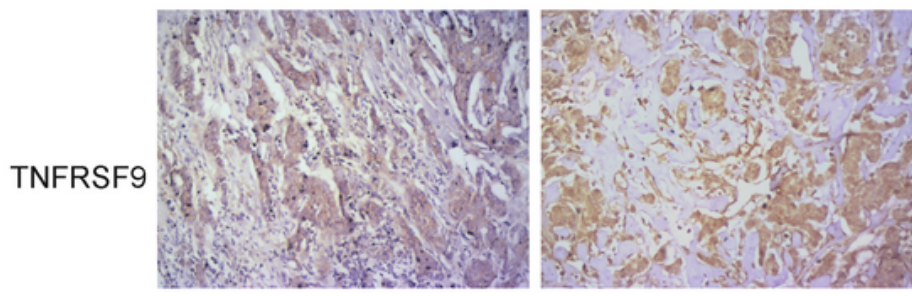

pLV-TNFRSF9

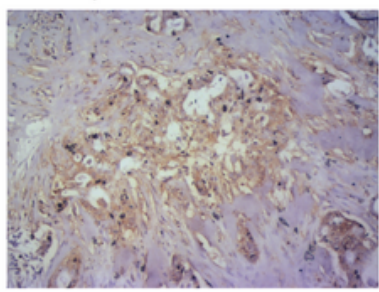

$\mathrm{NC}$

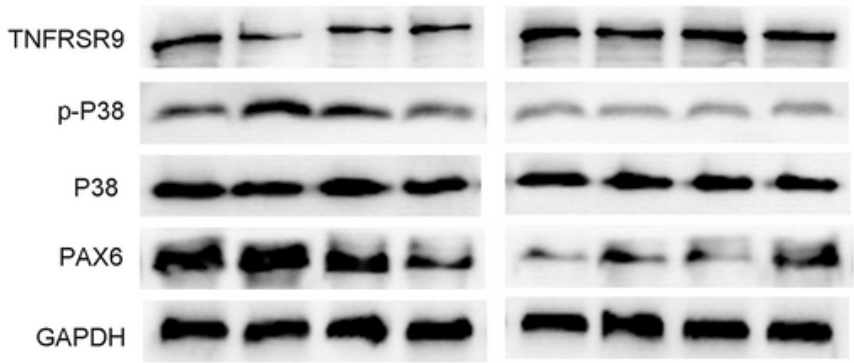

Figure 8 
TNFRSF9 overexpression inhibited breast cancer cell-induced tumor formation. (A) The representative appearances of extirpated xenograft tumors with implantation of pLV-TNFRSF9 transfected MCF-7 cells. (B) The size of tumors with implantation of pLV-TNFRSF9 transfected MCF-7 cells. (C) Pathological H\&E stained image of tumors with implantation of pLV-TNFRSF9 transfected MCF-7 cells. (D) Expression of Bcl-2 (upper panel) and TNFRSF9 lower panel) in tumors with implantation of pLV-TNFRSF9 transfected MCF-7 cells were detected by immunohistochemistry. (E) qRT-PCR assays for TNFRSF9 mRNA expression (upper panel) and PAX6 mRNA expression (lower panel) in tumors with implantation of pLV-TNFRSF9 transfected MCF-7 cells. (F) Western blot assays for TNFRSF9, p-P38, P38 and PAX6 protein expression in tumors with implantation of pLV-TNFRSF9 transfected MCF-7 cells. ${ }^{*} p<0.05,{ }^{\star \star} p<0.01,{ }^{\star \star \star} p<0.001$ 